\title{
POLÍTICAS PARA O ENSINO MÉDIO NO BRASIL: PERSPECTIVAS PARA A UNIVERSALIZAÇÃO
}

\author{
Savana Diniz Gomes Melo* \\ Adriana Duarte*
}

\begin{abstract}
RESUMO: Este artigo busca analisar as inflexões ocorridas nas políticas para o ensino médio no Brasil, a partir de 2007, problematizando o contexto em que foram produzidas e as contradições presentes nesse processo. Procura identificar as mudanças empreendidas, os discursos que lhes deram sustentação e as medidas e programas governamentais decorrentes. Retrata e analisa essas mudanças e suas implicações no âmbito dos estados, enfocando o caso de Minas Gerais. Com base nos argumentos reunidos, aponta algumas considerações e tendências observadas no rumo traçado pelas políticas atuais, no que tange às finalidades e à universalização dessa etapa da educação básica no país.
\end{abstract}

Palavras-chave: Políticas para o ensino médio. Finalidade. Universalização.

High SCHOOL POLICIES IN BRAZIL: PERSPECTIVES FOR THE UNIVERSALIZATION

ABSTRACT: This paper analyses the inflections of the high school policies in Brazil, from 2007 onwards. It questions the context in which they occurred and the contradictions present in the process. It searches to identify the main changes, the discourses that supported them and the measures and governmental programs that followed them. It depicts and analyses these

* Doutora em Educação e professora do Departamento de Administração Escolar, Faculdade de Educação, da Universidade Federal de Minas Gerais (UfMG).

E-mail: savanadiniz@yahoo.com.br

** Doutora em Educação e professora do Programa de Pós-Graduação em Educação, Faculdade de Educação da UfMG. E-mail: driduarte58@gmail.com 
changes and their implications in the states, focusing on Minas Gerais. Based on the gathered arguments, it stresses a few considerations and tendencies in the path traced by the current policies concerning the finalities and the universalization of this stage of the country's basic education.

Key words: Policies for high school. Finality. Universalization.

\section{Introdução}

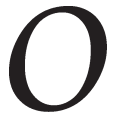

ensino médio no Brasil vem sendo historicamente objeto de conflito no campo educacional, tendência que adquiriu diferentes proporções em cada contexto em que invariavelmente se expressavam, sob distintos matizes, traços da dicotomia estrutural da sociedade cindida em classes e atravessada por sucessivos estágios de desenvolvimento, nos últimos duzentos anos, rumo à consolidação e hegemonia do modo de produção capitalista. Essa dicotomia também se expressa em aspectos estruturais do sistema de ensino, notoriamente conhecidos, dentre os quais pode ser destacada a dualidade entre o ensino propedêutico e o profissionalizante que, a rigor, guardam uma estreita relação de interdependência. Com efeito, as políticas para esses tipos de ensino só podem ser compreendidas em sua profundidade e extensão quando analisadas em conjunto e em articulação com a totalidade das recentes políticas para a educação básica e superior no país.

Com esse entendimento, neste artigo, que objetiva refletir sobre as políticas, programas e medidas dirigidas ao ensino médio no Brasil e em Minas Gerais, tecem-se também algumas referências sobre a educação profissional com o fim de evidenciar os aspectos mais relevantes dessa etapa da educação básica, a complexidade que a envolve e as perspectivas para a sua universalização.

\section{Ensino médio: políticas atuais}

Na década de 1990, com a aprovação da Lei n. 9.394/96, o ensino secundário recebeu a denominação de ensino médio, não obrigatório, destinado aos jovens de 15 a 17 anos egressos do ensino fundamental, e passou a contar com uma estrutura curricular única em todo o território nacional. $\mathrm{O}$ seu eixo estruturante passou a ser a necessidade 
de oferta de uma formação geral e polivalente que propiciasse a aquisição de saberes e competências básicas que preparassem os jovens para a vida. Em decorrência dessa lógica, emergem, em 2000, o Programa de Melhoria e Expansão do Ensino Médio e o Projeto Escola Jovem. Ambos, contando com financiamento do Banco Interamericano de Desenvolvimento (BID), tinham como objetivo apoiar a implementação da reforma curricular e estrutural e a expansão do atendimento no ensino médio no país pelas Unidades Federadas, com vistas à melhoria de sua qualidade e à ampliação de seu grau de cobertura, como modo de garantir maior equidade social (Brasil, 2000).

Passa a vigorar nesse contexto uma nova forma de conceber e promover a participação de jovens e adolescentes no campo educacional e social, propalada como protagonismo juvenil/alunos. Esta emerge alinhada às proposições da Comissão Econômica para a América Latina e o Caribe (CEPAL) relativas às novas exigências de formação dos trabalhadores para o exercício da chamada "moderna cidadania" (Ferretti, 2003). Esse tema é analisado por Zibas (2006), que identifica as diversas facetas do conceito protagonismo juvenil. Segundo ela, a participação dos jovens/alunos, tal como expresso nos documentos da reforma do ensino médio e veiculado por muitos autores, de um lado, abre perspectivas para desenvolvimento de ações solidárias no campo educacional e social, diante das necessidades imediatas da população. De outro, pode implicar a despolitização do olhar sobre as determinações da pobreza e, com isso, desviar o foco das preocupações para a ação individual ou mesmo coletiva, em detrimento do debate político e social. Desse modo, para a autora, o protagonismo juvenil pode promover valores, crenças, açóes de caráter mais adaptativo do que questionador. Resta analisar, na globalidade das políticas adotadas e da prática social, em que medida essa implicação se concretiza, o que seria tema para outros estudos.

A partir de 1997, a chamada reforma do ensino médio e da educação profissional determina que o ensino técnico seja ofertado de forma complementar, paralela ou sequencial e separado do ensino médio regular. A condição de modalidade conferida à educação profissional na Lei n. 9.394/96, com possibilidade de articular-se com as etapas e níveis do ensino regular sem deles ser parte integrante, confere-lhe um caráter secundário, que também se estende ao financiamento, à gestão 
e se reflete sobre os docentes que atuam nessa área. Impositivamente, mediante decreto, o modelo vigente há mais de três décadas na rede federal do país (Kuenzer, 1999) é substituído por um modelo que representasse uma alternativa em substituição à educação superior $(\mathrm{Cu}-$ nha, 2000).

No período que compreende o primeiro governo Lula (2004 a 2007), o Decreto n. 5.154/04 readmitiu ao conjunto das escolas médias no país a possibilidade de integrar o ensino médio à educação profissional. Porém, essa integração ficou a critério das escolas, dos sistemas e das redes de ensino, o que trouxe implicações. Na prática, as experiências foram limitadas em termos qualitativos e quantitativos. Nas redes estaduais de ensino, a oferta da educação profissional é secundarizada em razão da prioridade que a legislação nacional lhe atribui. A integração vem sendo promovida de forma pontual por meio de parcerias com o setor privado elou de programas-piloto nos quais se destacam a insuficiência ou inexistência de quadros próprios, entre outros, configurando uma situação de provisoriedade e de precariedade.

Um panorama da situação educacional do ensino médio no país a partir da década de 1990 é apresentado por Simóes (2008, 2009), apontando algumas tendências. O autor reúne indicadores obtidos em pesquisas oficiais diversas que, embora dispersas, com objetivos, metodologias e variáveis distintas, ajudam a refletir sobre os resultados das políticas empreendidas. Simões mostra que as matrículas no ensino médio no Brasil apresentaram expressivo aumento no período de 1991 a 2007. Enquanto em 1991 o total de matrículas era de 3.772.698 e as matrículas de jovens de 15 a 17 anos totalizavam 1.626.570, em 2000, esses números pularam para 8.192.948 e 3.565.240, respectivamente. Em 2007, os dados mostraram um pequeno crescimento no total de matrículas que chegou a 8.360 .664 e um expressivo aumento nas matrículas de jovens de 15 a 17 anos que chegou a 6.023.949. Suas análises da distribuição das matrículas, por turno, revelaram que o aumento se concentrou no ensino médio diurno, sobretudo a partir de 1997.

Simões verifica que esse aumento de matrículas ocorreu no segmento estadual, que passou de 2.472.964 em 1991 para 7.239.523 em 2007. Nas demais dependências administrativas, ocorreu redução das matrículas, sendo mais expressiva no segmento federal, seguido do particular. Ao estudar a transição do ensino médio e educação superior 
no Brasil, o autor concluiu que, do total de ingressos no ensino médio em 2003 (3.687.330), 1.858.615 chegaram a concluí-lo em 2005 e apenas 1.311 .533 ingressaram nos cursos de graduação, em 2006. Em relação ao trabalho dos jovens, ele identifica que, em 2006, do total de matriculados (34.709.467), 16.268.248 somente estudavam e 18.244.203 eram ocupados.

Pelo exposto, pode-se depreender que, no período de 1990 a 2000, verificou-se crescimento das matrículas no ensino médio. De 2000 a 2006, registrou-se estabilidade nas matrículas públicas no ensino médio e, a partir de 2006 e 2007, ocorreu queda nas matrículas. Ou seja, as políticas empreendidas e as medidas adotadas a partir de, embora tenham resultado crescimento em alguns momentos, não foram suficientes para enfrentar o problema da reduzida cobertura do ensino médio.

\section{Ensino médio a partir de 2007}

A partir de 2007, que compreende o segundo governo Lula, são criadas normas, desenvolvidos programas e medidas em relação ao ensino médio e à educação profissional que, embora com algumas diferenças, dão continuidade à política iniciada na gestão anterior e a ênfase é dada à melhoria desses tipos de ensino.

O primeiro aspecto a ser destacado refere-se ao processo deflagrado a partir da edição do Decreto n. 6.095/2007 e a aprovação da Lei n. 11.892/2008, para fins de constituição dos Institutos Federais de Educação, Ciência e Tecnologia (IF) e reorganização da Rede Federal de Educação Tecnológica. Ferretti (2011) chama a atenção para o papel cumprido por esses IF no processo de reforma do ensino médio e profissional e os desafios postos a eles em função da amplitude e verticalização de todos os IF com seus múltiplos campi em cada estado brasileiro; das expectativas sociais e governamentais dirigidas a estes institutos; das demandas em termos de seu papel social e de materialização da integração do ensino médio à educação profissional técnica nos moldes do proposto pelo Decreto n. 5.154/2004.

$\mathrm{O}$ segundo aspecto evidenciado diz respeito à Emenda Constitucional n. 59, que assegura a educação básica obrigatória e gratuita de 4 a 17 anos de idade. Embora essa expansão tenha sido interpretada 
no meio educacional como democratização do acesso ao ensino médio, a limitação da obrigatoriedade à faixa etária é compreendida como um limite da norma, que pouco ajuda a enfrentar o problema da sua universalização. Assim, uns veem a medida como fator de indução para a superação do caráter restrito que essa etapa do ensino tem apresentado ao longo da história e outros reivindicam que a obrigatoriedade e a gratuidade sejam garantidas à educação básica para todos, independentemente da idade.

O terceiro aspecto é a instituição do Programa Ensino Médio Inovador, também em 2009, como uma forma de incentivar as redes estaduais de educação, por meio de parceria com o Sistema $S$, a criar iniciativas inovadoras para o ensino médio mediante apoio técnico e financeiro do governo federal. A intenção manifesta é estimular as redes estaduais de educação a pensar novas soluções que diversifiquem os currículos com atividades integradoras, a partir dos eixos trabalho, ciência, tecnologia e cultura, para melhorar a qualidade da educação oferecida nessa fase de ensino e torná-la mais atraente. ${ }^{1} \mathrm{Na}$ primeira fase do programa, aderiram dezessete estados brasileiros, além do Distrito Federal, abrangendo o total de 357 escolas e 296.312 alunos, o que representa $3,7 \%$ do número de matriculados no ensino médio em todo o território nacional. ${ }^{2}$ Ainda são incipientes os dados sobre a implementação do programa e os estudos de seus resultados. Contudo, o Ministério da Educação (MEC) destaca como aspectos positivos o significativo crescimento das matrículas no ensino médio do sistema público estadual nos últimos anos; o aumento proporcional de alunos na faixa etária de 15 a 17 anos, que indica crescente resultado das políticas de correção de fluxo; a evolução dos resultados do Índice de Desenvolvimento da Educação Básica (IDEB), que alcançam a meta prevista para o país, ainda que admitindo a necessidade de atingir patamares mais altos, e que, diante da ampliação do universo de atendimento - que trouxe para o contexto escolar segmentos até então excluídos dessa etapa de escolarização -, foi possível retomar o crescimento de resultados em avaliações do desempenho escolar.

Por outro lado, há registros em pesquisas com docentes de escolas participantes do Programa sobre dificuldades enfrentadas para colocar em prática as medidas relativas a aspectos pedagógicos expressos no currículo escolar; as mudanças na organização do trabalho pedagógico; e a valorização dos docentes, que necessitam permanecer mais 
tempo na escola sem que as condições objetivas lhes sejam garantidas. Esses são indícios que, entre outros, devem ser mais bem estudados.

Em quarto lugar, destaca-se a reelaboração, em 2009 e 2010, da concepção do Exame Nacional do Ensino Médio (ENEM), criado em 1998. Este passa a ter como objetivo induzir a organização curricular do ensino médio, começa a ser adotado como vestibular unificado para as universidades federais, a certificar jovens e adultos e a ser aceito para verificação do desempenho acadêmico dos ingressantes no ensino superior. Com a mudança ganham maior expressão às preocupações dirigidas ao ENEM desde sua origem, referentes à concepção que orienta o sistema de avaliação instalado no país com a Lei n. 9.394/06, sobretudo no que tange a adoção da lógica privada na esfera educativa e seus efeitos perversos. A despeito disso, ainda que considerados os seus limites, o Exame tem apontado os piores resultados nas escolas públicas estaduais, haja vista a avaliação do ENEM de 2009.

Em quinto lugar, chama-se a atenção para o tratamento dado ao protagonismo juvenil no governo Lula e os indícios já perceptíveis de continuidade dessa perspectiva no governo Dilma. O governo federal divulga a ideia de que a ênfase dada a esse protagonismo se justifica "pelo reconhecimento dos papéis de distintos atores na formulação, validação, implementação e avaliação de políticas públicas de juventude". Afirma-se ainda que as iniciativas nesse campo não representam a tentativa de "minimizar as responsabilidades do Estado ou de substituir o protagonismo dos vários movimentos juvenis". ${ }^{3}$ Com efeito, a partir de 2005, inicia-se o processo de institucionalização das Políticas para a Juventude no Brasil, cuja discussão havia sido iniciada em 2003. Nesse processo, destacam-se a criação da Secretaria e do Conselho Nacional de Juventude (2005); do Programa Nacional de Inclusão de Jovens: Educação, Qualificação e Ação Comunitária (PROJovem) (2006); do Programa Universidade para Todos (Prouni) (2005); do Programa de Apoio a Planos de Reestruturação e Expansão das Universidades Federais (Reuni) (2007); os Pontos de Cultura e as Praças da Juventude, entre outros que, apesar de não serem exclusivos de juventude, atendem, mormente, os jovens brasileiros pertencentes às camadas populares, em situação de defasagem escolar, desemprego e vulnerabilidade social.

Como novidades propaladas pelo MEC, essas iniciativas têm encontrado defensores que as veem como tentativas de democratizar o 
acesso e melhorar a qualidade do ensino. Todavia, há também críticos que temem os seus efeitos perversos, tais como a diferenciação e o estímulo à competitividade entre as escolas; o estabelecimento de rankings; a privatização e a degradação da educação - temas já amplamente tratados na literatura da área. Afora isso, as consecutivas falhas ocorridas com o novo ENEM, referentes ao vazamento de provas em 2009, erros na impressão de provas em 2010 e problemas para inscrições no Sistema de Seleção Unificada (SISU) em janeiro de 2011, vêm implicando perda de credibilidade ao Exame e ao próprio MEC e foram inclusive a causa da demissão de dois presidentes do Instituto Nacional de Estudos e Pesquisas Educacionais (INEP). ${ }^{4}$

Em meio a essas medidas, os indicadores educacionais relativos ao ensino médio, ainda que limitados e descontínuos, permitem algumas inferências e análises. O Censo da Educação de 2008 mostra que esta etapa de ensino cresceu modestamente no país. Os dados apontam um aumento de 400 mil alunos no ensino médio estadual e municipal, o que representa quase $7 \%$ mais estudantes do que em 2007.

Em 2009, o ensino médio contou com quase 30 mil alunos a menos que em 2008. A queda foi de 0,3\%. A matrícula correspondeu a apenas 50\% dos jovens de 15 a 17 anos - idade escolar correspondente. A Pesquisa Nacional por Amostra de Domicílio (PNAD) de 2009 mostrou a existência de 1,4 milhão de jovens entre 15 e 17 anos fora da escola. O Censo Escolar da Educação Básica registrou em 2009 um total de 8.280.875 estudantes cursando o ensino médio regular, 4.577.517 matriculados na educação de jovens e adultos e 837.011 na educação profissional. $\mathrm{O}$ ensino médio integrado à educação profissional representava apenas $17 \%$ das matrículas do ensino profissional e o ensino profissional integrado representava apenas $12 \%$ do total de matrículas do ensino médio.

Os dados mostram que as matrículas nessa etapa da educação básica têm mantido equilíbrio nos últimos anos, o que para o governo pode indicar que a cobertura vem aumentando lentamente, considerando-se outras variáveis. Para o ex-presidente do INEP, Reynaldo Fernandes, ${ }^{5}$ a queda nas matrículas do ensino médio observada em 2009 não denota, necessariamente, aumento da evasão escolar. Em sua avaliação, o resultado reflete a redução da repetência, que implica a 
melhoria no fluxo escolar, e a diminuição na taxa de natalidade brasileira a partir dos anos de 1980.

Contudo, os indicadores educacionais sinalizam que o problema da cobertura do ensino médio persiste. É alto o índice de jovens que se encontram fora da escola, sobretudo aqueles que estão acima da faixa etária de 14 a 17. Pode-se indagar sobre o que se fez para mudar essa situação no país nas últimas décadas, com vistas à universalização, e que perspectivas se podem vislumbrar no futuro próximo. Sabe-se que foram adotadas iniciativas supostamente voltadas para a melhoria do ensino médio: transferiu-se a responsabilidade da oferta prioritária para os estados; modificou-se a sua estrutura e relação com a educação profissional; introduziu-se o currículo por competências e a avaliação em larga escala, passando a utilizá-la como forma de ingresso no ensino superior; adotou-se a política de fundos e experimentam-se novas propostas pedagógicas que buscam ultrapassar os limites tradicionais da organização curricular por disciplinas. Paralelamente, ajustou-se a oferta à faixa etária correspondente e retiraram-se do sistema regular os estudantes com defasagem idade/série. Mas essas medidas não foram suficientes para ampliação da cobertura e, tampouco, da melhoria da qualidade do ensino oferecido.

Para o futuro, vislumbram-se novas expectativas depositadas, sobretudo, no novo Plano Nacional de Educação (PNE) para o período de 2011-2020. O Projeto de Lei que apresenta a proposta de PNE, em tramitação na Câmara dos Deputados, contém como uma de suas metas "Universalizar, até 2016, o atendimento escolar para toda a população de 15 a 17 anos e elevar, até 2020, a taxa líquida de matrículas no ensino médio para 85/\%, nessa faixa etária”. Para tanto, são apontadas doze estratégias que não são suficientes para enfrentar os problemas do ensino médio e, em geral, referem-se à continuidade e aprimoramentos de iniciativas do governo federal, comentadas anteriormente. Chama a atenção, entretanto, o item que se refere ao redimensionamento da oferta por turnos e a redistribuição territorial de escolas (Item 12). Embora essas ações sejam necessárias, é curioso que a ideia prevalente seja a de reordenamento e não a de ampliação da oferta e dos recursos para tanto. Essa opção política também se expressou nos planos de governo apresentados pela candidata a presidenta, Dilma Rousseff. É curioso que esta tenha explicitado em seu primeiro Programa de Governo ${ }^{6}$ a 
necessidade de "melhorar a qualidade da educação básica" e "promover uma reforma político-pedagógica no ensino médio", mas que não tenha citado a necessidade de ampliação da oferta de vagas públicas. $\mathrm{O}$ documento, no item $A$ dimensão estratégica da juventude para um novo desenvolvimento, explicita o sentido estratégico atribuído à juventude, compreendendo-a como impulsor de reformas democráticas e populares que garantam a integração das novas gerações ao processo democrático e ao projeto de desenvolvimento sustentável. O texto também explicita a intenção de Dilma de dar prosseguimento à Política Nacional de Juventude, implantada a partir de 2005. Para tanto, afirma a necessidade e assume quatro compromissos que também, no geral, referem-se ao aprimoramento de medidas já existentes. Um deles é especialmente dedicado ao ensino médio e refere-se à promoção de uma reforma político-pedagógica nessa etapa da educação básica.

No segundo documento substitutivo, intitulado "Os 13 compromissos programáticos de Dilma para debate na sociedade brasileira", 7 há um enxugamento significativo das propostas, em diversos aspectos considerados polêmicos no contexto da campanha eleitoral. No item 7, dedicado à educação, à cidadania e ao desenvolvimento, todas as referências relativas ao ensino médio desaparecem e passa a vigorar a promessa geral de expansão e melhoria do ensino público. Reitera-se, entretanto, o compromisso de garantir, principalmente aos jovens, uma escola de qualidade, que combine ensino e capacitação para o trabalho.

Mais preocupante, entretanto, parece ser o anúncio de Dilma Roussef em entrevista e no Twitter, durante a campanha presidencial de 2010, de criar um programa para facilitar o acesso de estudantes que desejam cursar o ensino médio a vagas em escolas particulares. ${ }^{8} \mathrm{~A}$ proposta foi batizada pela então candidata de ProMédio e contaria com dois mecanismos: bolsas inspiradas no PROUNI, que concede auxílio de estudo em universidade privadas; e financiamento com prazos longos e baixos juros. Em fevereiro de 2011, entretanto, Dilma anunciou o lançamento do Programa Nacional de Acesso à Escola Técnica (PRONATEC), que prevê bolsas para cursos técnicos em escolas privadas e financiamento estudantil.

A questão que se coloca para programas dessa natureza no ensino médio e técnico é a mesma expressa para a educação superior por Catani et al. (2006, p. 125): “o PROUNI é um instrumento de democratização 
da educação superior no Brasil ou um mero programa de estímulo à expansão das Instituiçôes de Ensino Superior (IES) privadas?”. Esses autores terminam lamentando a dificuldade de responder a questão por vários motivos, dentre os quais se destaca a falta de informações sobre o programa por parte do Ministério (idem, p. 137-138).

Ante tais dificuldades para a análise e tamanha dúvida sobre quem mais se beneficia com o programa, pode-se indagar se o Pró-Médio-Profissional, somado às iniciativas em curso já citadas e que devem ser mantidas e consolidadas nos próximos anos (novo ENEM e Ensino Médio Inovador), e a eminência de mudanças previstas relativas às Diretrizes Curriculares Nacionais para a Educação Profissional Técnica de Nível Médio, que se encontram em discussão no Conselho Nacional de Educação ( $\mathrm{CNE}$ ), podem ser considerados como medidas políticas que efetivamente corroboram o enfrentamento do grande desafio histórico da educação brasileira em relação ao ensino médio: universalizar sua oferta pública, conferir-lhe qualidade e identidade própria no sistema educativo, potencializar sua dimensão formativa sob a concepção de escola unitária e de escola politécnica, entre outros. Tais princípios são apontados no documento final da Conferência Nacional de Educação (CONAE). Entretanto, para que eles se efetivem na prática, torna-se necessária a ampliação de recursos para a educação básica para além da política de fundos, o que, lamentavelmente, ainda parece estar longe do horizonte de possibilidades no cenário nacional.

\section{O ensino médio em Minas Gerais}

A política atual de educação no estado de Minas Gerais começou a ser esboçada na década de 1990, nas administrações dos governadores Hélio Garcia (1991-1994) e Eduardo Azeredo (1995-1998). Esse estado é considerado pioneiro na implantação de paradigmas para a educação que, segundo Oliveira (2000), reúnem as demandas de transformação produtiva com equidade.

As mudanças instituídas na política de educação, nas gestōes Garcia e Azeredo, estavam voltadas para a desconcentração administrativa, atribuindo à escola maiores responsabilidades no que se refere à administração dos recursos financeiros, processos de formação de professores, fluxo escolar e depositando sobre a unidade escolar e os 
agentes que a integram a responsabilidade final sobre os resultados educacionais. Essas reformas repercutiram em alterações significativas na composição, estrutura e gestão da rede estadual de educação de Minas Gerais e tinham como lema "Minas aponta o caminho" (Oliveira, 2000).

Nesses dois governos, foram implantadas medidas como: organização do ciclo básico (promoção automática); programa de avaliação da escola pública; mudanças na forma de escolha dos diretores; formação dos colegiados escolares; descentralização administrativa e pedagógica das escolas; capacitação dos professores em serviço e por meio de educação continuada; capacitação dos dirigentes escolares; melhoria da rede física, racionalização do espaço escolar e implantação de um sistema de monitoramento e avaliação escolar (Pedrosa \& Sanfelice, 2005).

Destacou-se na gestão Hélio Garcia a implantação do Programa de Qualidade Total em Educação, que levou a tecnologia gerencial do Controle da Qualidade Total às escolas da rede pública estadual e a efetivação de novas parcerias entre estado/município e empresas privadas.

No governo Azeredo foi lançado o Programa de Aceleração da Aprendizagem, que visava a superar a ocorrência de altas taxas de distorção idade/série em toda a educação básica do estado. Esse programa propunha classes aceleradas para alunos que não conseguiram concluir sua escolaridade na faixa etária correspondente e envolvia dois projetos: "Acertando o passo" (voltado para as séries finais do ensino fundamental) e "A caminho da cidadania" (voltado para o ensino médio). Este último, destinado à regularização do fluxo nesta etapa de ensino, estendia-se também ao atendimento de jovens evadidos da escola. Nesse projeto, os currículos eram organizados semestralmente, de forma a permitir que o aluno pudesse acelerar o seu processo de aprendizagem e seus estudos, reintegrando-se ao fluxo escolar (sEE/MG, 1998).

A busca de melhoria da qualidade do ensino médio na rede estadual de Minas Gerais, na gestão Azeredo, tinha como proposta que as escolas estaduais se concentrassem na formação propedêutica e estabelecesse parcerias com os setores produtivos e de serviços para oferecer o curso técnico. Esses cursos se constituiriam em uma alternativa 
para os estudantes que optassem pelo ensino profissional, em forma de cursos pós-médios, que poderiam ser realizados concomitantemente ao ensino médio ou após a sua conclusão. Nesse sentido, os cursos profissionalizantes oferecidos pelas escolas estaduais deveriam ser submetidos a um processo de avaliação que objetivava identificar suas possibilidades e decidir sobre sua continuidade ou não. Ou seja, recomendava-se que esses cursos deveriam ser ofertados pelo Estado em parceria com organizaçôes sociais, instituições particulares, instituições ou empresas governamentais, interessadas na habilitação profissional (Pires, s/d).

O fortalecimento do processo de integração com os municípios foi outro aspecto que se destacou na atuação desse governo. $\mathrm{O}$ processo de municipalização era reivindicado pelo estado, considerando melhor utilização da capacidade física instalada nos municípios e também a otimização das verbas públicas aplicadas em educação. Essa integração entre o estado e as prefeituras dos municípios mineiros era desenvolvida por meio de acordos que, segundo Oliveira (2000), reduziam-se à transferência aos municípios do atendimento de alunos matriculados, prioritariamente, nas quatro primeiras séries do ensino fundamental. Nesses acordos, o estado, em alguns casos, comprometia-se a oferecer o ensino médio, por meio de nucleação, em troca da transferência do atendimento do ensino fundamental ao município. A política de nucleação de escolas fechou unidades isoladas instaladas principalmente em zonas rurais, o que provocava o deslocamento dos estudantes para os centros urbanos mais próximos, cabendo ao poder público municipal se responsabilizar pelo transporte. Oliveira (2000) registra ainda que, no período de 1994 a 1998, foram municipalizadas 2.863 escolas estaduais. A redistribuição de recursos por meio do Fundo de Manutenção e Desenvolvimento do Ensino Fundamental e de Valorização do Magistério (FUNDEF) veio fortalecer o processo de convencimento das prefeituras a arcarem com o atendimento ao ensino fundamental.

A universalização do ensino fundamental e a obrigatoriedade de oferta pública aumentaram o número de concluintes dessa etapa, produzindo uma pressão social para a expansão do ensino médio, confirmado pelo número significativo de matrículas para a etapa final da educação básica ofertadas pelo estado de Minas Gerais. No entanto, a ausência de fundos específicos para o ensino médio colocou-o na dependência do ensino fundamental, tanto no que se refere à sua 
manutenção, quanto ao espaço físico, pessoal e materiais necessários. Há que se destacar ainda que os programas e projetos realizados por esses dois governos obtiveram recursos dos organismos internacionais na busca de equalização das medidas propostas. Para o ensino médio, essas "parcerias" eram consideradas fundamentais, pois essa etapa do ensino não recebia recursos diretos para o seu custeio.

No governo de Itamar Franco (1999-2002) foi implementado o Projeto "Escola Sagarana", que era definida como um conjunto de planos e atitudes baseado no compromisso social com as futuras gerações, pela composição integral da política educacional de Minas Gerais e a sua identidade com a cultura e o povo mineiro. Uma das metas desse programa era a garantia de matrícula no ensino médio, até 2003, de pelo menos $80 \%$ dos egressos do ensino fundamental (SEE/MG, 1999).

A demanda pelo ensino médio aumentou no decorrer de 1999/ 2002, considerando, além do processo de universalização do ensino fundamental, o retorno dos que haviam deixado a escola, as exigências de escolaridade impostas pelo mercado de trabalho e as ações dos programas de aceleração de estudos e redução de idade para conclusão do ensino fundamental (15 anos), por meio de exames de suplência (Brasil, Lei n. 9.394/1996, art. 38, inc. I).

Para atender a demanda de vagas para o ensino médio, a rede estadual adotou os seguintes critérios: aumento de turmas nas escolas estaduais que já ofereciam o ensino médio e implantação da etapa do ensino médio em escolas que só ofereciam ensino fundamental. Tais medidas baseavam-se no estudo do fluxo escolar, obedecendo também a critérios relativos ao zoneamento escolar, a existência de espaços físicos adequados e pessoal habilitado e/ou que poderia ser autorizado para o exercício da docência. Exigia-se, ainda, a comprovação de demanda mínima de 120 alunos, organizados em três turmas, para início do funcionamento imediato ou gradativo do curso, bem como a demonstração, pelo estudo do fluxo escolar, da existência de demanda suficiente nas séries finais do ensino fundamental para prosseguimento de estudos; devia-se, ainda, observar a faixa etária de 15 a 17 anos. Alunos com idade superior a 18 anos, bem como aqueles que pleiteavam retornar à escola pública, eram atendidos nos Centros de Educação Continuada (CESEC), nas telessalas espalhadas por Minas Gerais, e por meio dos exames de suplência (Oliveira, 2002). 
No período de 2003-2010, esteve à frente do governo de Minas Aécio Neves. Este, em seus dois mandatos, introduziu o Programa Choque de Gestão, ${ }^{9}$ com o objetivo de melhorar a qualidade e reduzir os custos dos serviços públicos mediante a reorganização do arranjo institucional e do modelo de gestão. Para a área da educação foram fomentadas iniciativas destinadas à melhoria da qualidade do ensino, considerando a perda de posição do estado nos resultados do Sistema de Avaliação da Educação Básica (SAEB), em 2003, em comparação com os resultados de 2001, ou seja, Minas Gerais passou do primeiro para o quarto lugar no ranking.

Os indicadores educacionais relativos ao ano de 2002 mostravam que a taxa de atendimento escolar, na faixa de 15 a 17 anos, era de $88,5 \%$, considerando todas as redes de ensino. Em números absolutos, havia 914.943 alunos matriculados no ensino médio e, destes, 464.343 tinham idade superior a 17 anos. Na rede estadual, a taxa de abandono no ensino médio era de $17,9 \%$, alcançando $23,1 \%$ no $3^{\circ}$ ano e a taxa de distorção idade/série chegava a 52,6\%, com um máximo de 57,5\% no último ano (SEE/MG, 2003). Ou seja, menos da metade dos jovens na faixa etária de 15 a 17 anos conseguia chegar ao ensino médio na idade apropriada, além de não se conseguir assegurar a permanência de todos aqueles que se matriculavam nesta etapa de ensino.

Para alterar esse quadro, a Secretaria de Estado de Educação (SEE) propôs uma série de medidas como: a atualização dos conteúdos curriculares; o aperfeiçoamento dos métodos de ensino e aprimoramento dos recursos didáticos; a participação dos jovens na vida da escola e da comunidade; e a oferta de alternativas de atendimento, em função das características e necessidades dos alunos (SEE/MG, 2003). Além disso, recomendava-se investir na formação para o trabalho, na integração entre ensino médio e educação profissional. Segundo o governo, essas medidas tinham como objetivo assegurar a permanência dos alunos matriculados no ensino médio e universalizar essa etapa de ensino.

Para o ensino médio, foi aprovada uma reorganização da oferta do ensino regular, da educação de jovens e adultos e dos projetos de aceleração de estudos, de acordo com a idade dos estudantes. Ou seja, no ensino médio regular diurno matriculavam-se os alunos sem defasagem idade/série. O ensino médio regular noturno estava voltado aos 
alunos com pelo menos um ano de defasagem idade/série e aos estudantes na idade considerada apropriada, que apresentassem justificativa para não frequentar o curso diurno. E, por fim, a Educação de Jovens e Adultos (EJA) e o Projeto de Aceleração de Aprendizagem, ambos no horário noturno, destinados aos alunos com 19 ou mais anos de idade (SEE/MG, 2003). Essa era uma fórmula para, entre outros aspectos, procurar corrigir a grande distorção idade/série existente no ensino médio.

Em relação à reorganização curricular, propôs-se a seguinte fórmula: no primeiro ano do ensino médio, os Conteúdos Básicos Comuns ( de oferta do ensino médio. No segundo ano, os conteúdos eram distribuídos em duas grandes áreas: Ciências Humanas ou Ciências Naturais. Cada uma dessas áreas apresentava um subconjunto específico de disciplinas dos conteúdos básicos comuns, que deviam ser ensinados com tratamento mais aprofundado. O estudante faria o elenco de disciplinas da área que escolhesse ou que fosse encaminhado pela escola. No terceiro ano (ensino médio regular diurno) e quarto ano (ensino médio regular noturno), a escola tinha a "liberdade" de ensinar conteúdos novos que ultrapassassem os $\mathrm{CBC}$, ampliando a formação dos alunos. Se houvesse número suficiente de estudantes, eles podiam ser distribuídos em três áreas: Ciências Humanas, Ciências Exatas e Ciências Biológicas, cada uma com o seu elenco específico de disciplinas (SEE/MG, 2006). A nova organização curricular começou a ser implantada, em 2006, no primeiro ano do ensino médio, nas escolas da rede estadual chamadas de Escolas Referência. Estas foram selecionadas pela SEE entre as maiores e mais tradicionais de Minas e que possuíam o reconhecimento da comunidade em que atuavam. Eram 223 escolas, com cerca de 350 mil alunos, distribuídas por mais de 100 municípios (SEE/MG, 2006).

Em 2007, foi atualizado o Programa de Educação Profissional (PEP) com vistas a atender a demanda de jovens por mais oportunidades de formação profissional básica. Nessa versão, o programa abrangeu alunos da rede estadual de ensino matriculados no $2^{\circ}$ e $3^{\circ}$ anos do ensino médio, ou no $1^{\circ}$ e $2^{\circ}$ anos de Curso de EJA de ensino médio na modalidade presencial, além de egressos do ensino médio de qualquer rede de ensino, sem limitação de idade. Em 2008, foi criado o 
Programa Educacional de Atenção ao Jovem, considerado um instrumento de formação dos jovens estruturado a partir de uma visão afirmativa da juventude. O foco desse programa, segundo a SEE, é o jovem como fonte de iniciativas, de compromisso e soluçôes para a sua comunidade, por meio de ações de caráter educativo e participativo. Esse programa se iniciou voltado para a discussão da temática da sexualidade, mas hoje o seu foco é o protagonismo juvenil e está dividido em três áreas temáticas: sexualidade e afetividade; adolescência e cidadania; mundo do trabalho e perspectiva de vida. ${ }^{10}$

Em 2010, o vice-governador Antônio Anastasia assumiu o governo, sendo reeleito para o mandato de 2010-2014. Em seu plano de governo, na área de Educação, especificamente ao que se refere ao ensino médio, esse governador assumiu o compromisso de ampliar as oportunidades de acesso à educação profissional técnica com a criação de 400 mil novas vagas do PEP. Essa meta foi apresentada em conjunto com a implantação de zonas de desenvolvimento regional para estimular a instalação de empresas nos municípios, de acordo com a vocação econômica local. Outra proposta contida nesse plano é a ampliação do número de vagas no turno diurno destinadas ao ensino médio regular, dos atuais $60,32 \%$ para $75 \%$ em quatro anos.

Como se pode constatar, as políticas educativas implantadas em Minas Gerais abriram o leque de reformas educacionais implantadas no Brasil e estão em consonância com os projetos propostos pelo governo federal, acompanhando os programas e projetos implementadas na gestão de Fernando Henrique Cardoso e, posteriormente, no governo Lula, mesmo que em relação a este último se posicionasse como oposição. No entanto, verificou-se que as principais políticas nacionais direcionadas ao ensino médio não só tiveram e continuam tendo eco também no estado de Minas Gerais, como muitas vezes se anteciparam, o que confirma a aderência das políticas adotadas com o projeto reformador da educação no país, a partir de 1990.

\section{Considerações finais}

Com base na produção acadêmica, nos dados oficiais sobre a situação do ensino médio no país e nos documentos de governo estudados, são apontadas algumas constataçóes e consideraçóes acerca 
Políticas para o ensino médio no Brasil: perspectivas para a universalização

das políticas e programas em curso e as perspectivas para a universalização. A despeito das inúmeras e propaladas medidas adotadas a partir de 1990, verifica-se a estagnação das matrículas no ensino regular, a partir de 2000, na faixa etária de 15 a 17 anos, e a existência de um grande contingente de jovens acima de 18 anos "excluídos" da escola. A alternativa apresentada para esses jovens foi a educação de jovens e adultos, situada fora do ensino regular. Foram enfatizadas e empreendidas iniciativas de reforma curricular do ensino médio visando à melhoria de sua qualidade, porém são escassas as produções acerca dos resultados que possam avaliar o alcance dessas iniciativas e que tipo de integração está sendo efetivamente privilegiado. Disseminou-se a nova noção de protagonismo juvenil/estudantil como componente da gestão escolar compartilhada, o que, de um lado, pode estar corroborando com a despolitização dos estudantes e, de outro, abrindo espaços para florescimento e ou fortalecimento de movimentos estudantis, a exemplo das manifestações dos estudantes secundaristas contra as políticas consideradas nocivas à educação pública, verificadas no período em vários estados brasileiros - como São Paulo e Rio de Janeiro, em 2009, 2010 e 2011 -, emblemáticas do aumento da politização desse segmento. Tal fenômeno indica a necessidade de olhar com atenção para esse novo movimento estudantil secundarista que emerge no Brasil, assim como também em outros países da América latina (Chile e Argentina), para compreender outras dimensões e potencialidades do dito protagonismo estudantil.

Em geral, os programas federais têm sido marcados pelo caráter de focalização em estudantes que apresentam defasagens (sociais, econômicas, escolares) sob a justificativa de busca de inclusão social e, não raro, pela transferência de recursos públicos para o setor privado, sobretudo o Sistema S, em detrimento da expansão e da melhoria da oferta pública.

Essas constatações genéricas para o país são também válidas para a experiência do estado de Minas Gerais, destacando-se o seu pioneirismo na implementação das políticas e programas que marcaram o período analisado. Vale lembrar que, mesmo durante o governo Lula, Minas, que se colocava como oposição, não aderiu abertamente aos programas federais e implementou, sob diferentes nominações, muitas iniciativas com significativa equivalência no tocante a objetivos e meios 
expressos nos programas federais, a exemplo da reorganização curricular do ensino médio regular, da ênfase à EJA e do PEP, em parceria com o setor privado, entre outras.

Em termos de perspectiva de respostas aos desafios colocados ao ensino médio, pode-se considerar que a maior parte das expectativas está dirigida à aprovação do novo PNE. Contudo, o Projeto de Lei em discussão apresenta metas e estratégias restritas e frágeis, senão inócuas para enfrentamento do desafio de sua universalização e qualidade social. Sabe-se que a aprovação de leis não implica sua efetiva aplicação na realidade. No entanto, o avanço legal traz em si o reconhecimento do direito e mecanismos concretos para efetivá-lo. Nesse momento crucial, as atenções estão voltadas para a discussão e apresentação de emendas ao projeto, afinadas aos interesses em disputa - mais uma vez polarizada entre os defensores da educação pública e os privatistas. Estes acionam fortemente os políticos orgânicos aos seus projetos, ao passo que os defensores da educação pública reinstalam o Fórum Nacional em Defesa da Escola Pública para fortalecer, sistematizar, expressar suas prioridades e fazer constar propostas. O prazo para tanto é curto, as forças são desiguais, as estratégias são distintas, mas o debate está aberto, assim como estão por vir os possíveis avanços a serem conquistados para a educação pública nesse conflituoso processo.

\section{Notas}

1. Mais detalhes estão disponíveis em: < http://portal.mec.gov.br/index.php?option=com_ content $\&$ view $=$ article $\&$ id $=13439$ : ensino- medio - inovador $\&$ catid $=195:$ seb-educacao basica $\&$ Itemid $=1037>$.

2. Mais detalhes estão disponíveis em: <http://gestao2010.mec.gov.br/o_que_foi_feito/ program_39.php>.

3. Disponível em: <http://www.planalto.gov.br/secgeral/frame_juventude.htm>.

4. Reynaldo Fernandes, em 2009, e Joaquim Soares Neto, em 2011.

5. Disponível em: <http://oglobo.globo.com/educacao/mat/2009/11/30/numero-de-matriculas-no-ensino-basico-cai-1-2-914987439.asp>.

6. $1^{\circ}$ Documento entregue ao Tribunal Superior Eleitoral por ocasião do registro de sua candidatura, em 2010, posteriormente substituído.

7. Disponível em: <http://www.pt.org.br/portalpt>.

8. Disponível em: <http://www.opantaneiro.com.br/noticias/eleicoes-2010/97299/dilmaquer-criar-programa-para-ensino-medio-inspirado-no-prouni>. 
9. Disponível em: <www.seplag.mg.gov.br>.

10. Disponível em: <https://www.educacao.mg.gov.br/projetos $>$.

\section{Referências}

BRASIL. Ministério da Educação. Secretaria de Educação Média e Tecnológica. Programa de melhoria e expansão do Ensino Médio: Projeto Escola Jovem, síntese. Brasília, DF: MEC/SEMTEC, 2000. Disponível em: <http://portal.mec.gov.br/setec/arquivos/pdf/Escola\%20Jovem.pdf>. Acesso em: 20 dez. 2010.

CATANI, A.M.; HEY, A.P.; GILIOLI, R.S.P. PROUNI: democratização do acesso às Instituições de Ensino Superior? Educar, Curitiba, n. 28, p. 125-140, 2006.

CUNHA, L.A. O ensino profissional na irradiação do industrialismo. São Paulo: UNESP; Brasília, DF: FLACSO, 2000.

FERRETTI, C.J. A reforma do ensino médio: uma crítica em três níveis. Linguagens, Educação e Sociedade, Teresina, n. 9, p. 41-49, jan./ dez. 2003.

FERRETTI, C.J. A educação profissional no PNE: o papel dos Institutos Federais de Educação, Ciência e Tecnologia. In: SEMINÁRIO DE educaÇÃo Brasileira, 3., Campinas, 2011. Anais... Campinas: Cedes, 2011.

KUENZER, A. Ensino de $2^{\circ}$ grau: o trabalho como princípio educativo. São Paulo: Cortez, 1992.

KUENZER, A. A reforma do ensino técnico e suas conseqüências. In: Ferretti, C.J.; Silva Junior, J.R.; Oliveira, M.R.N.S. (Org.). Trabalho, formação e currículo: para onde vai a escola? São Paulo: Xamã, 1999.

MACHADO, L.R.S. Educação e divisão social do trabalho: contribuição para o estudo do ensino técnico industrial brasileiro. São Paulo: Cortez, 1989.

MATTOS, M.J.V.M. A reforma educacional de Minas Gerais: uma experiência de desconcentração. Revista online Bibl. Prof. Joel Martins, Campinas, v. 2, n. 1, p. 1-19, out. 2000. 
MINAS GERAIS. Secretaria de Estado de Educação (SEE/MG). A educação pública em Minas Gerais: o desafio da qualidade 2003/2006. Belo Horizonte: SEE/MG, 2003. Disponível em: <http://www.educacao. mg.gov.br/politica>. Acesso em 10/02/2011

MINAS GERAIS. Secretaria de Estado de Educação (SEE/MG). Novo Plano Curricular: Ensino Médio. Belo Horizonte: SEE/MG, 2006. 60p.

OLIVEIRA, D.A. Minas aponta o caminho: as reformas educacionais nos anos 90. In: Oliveira, D.A. Educação básica: gestão do trabalho e da pobreza. Petrópolis: Vozes, 2000. p. 244-306.

OLIVEIRA, M.A.C. Atendimento do ensino médio no estado de Minas Gerais: ensino médio: os desafios da reforma. Belo Horizonte: SEE/MG, 2002. (Lições de Minas, v. 16).

PEDROSA, L.D.; SANFELICE, J.L. Minas aponta o caminho: o processo de reforma da educação mineira. In: SEMINÁRIO NACIONAL ESTADO e políticas SOCIAIS NO BRAsil, 2., 2005, Cascavel. Anais... Cascavel: UNIOESTE, 2005. p. 1-15.

PIRES, R.P. Uma análise sobre políticas públicas e educação profissional em Minas Gerais no período de 1995-2000. Caxambu: ANPEd, [s.d.].

SIMÕES, C.A. Vinculos entre a educação e trabalho. Trabalho apresentado no Seminário Internacional Educação Secundária: direito, inclusão e desenvolvimento, Buenos Aires, UNICEF, 4 set. 2008.

SIMÕES, C.A. O ensino médio no Brasil: realidade e desafios. Trabalho apresentado no Seminário de Políticas Públicas para o Ensino Médio, Universidade Federal de Minas Gerais, Belo Horizonte, 10 de junho 2009.

ZIBAS, D.M.L; FERRETTI, C.J.; TARTUCE, G.L.B.P. A reforma do ensino médio e o protagonismo de alunos e pais. In: VITAR, A. et al. (Org.). Gestão e inovaçôes no ensino médio: Argentina, Brasil, Espanha. Brasília, DF: Líber Livro, 2006. p. 83-138.

Recebido em 24 de março de 2011. Aprovado em 28 de abril de 2011. 